\title{
Implementation of artificial intelligence in the electric power industry
}

\author{
Andrey Sozontov, Maria Ivanova*, and Arthur Gibadullin \\ State University of Management, Ryazanskiy Avenue 99, Moscow, Russia
}

\begin{abstract}
The article deals with the possibility of the implementation of artificial intelligence, which will improve the efficiency of national economy, including the energy industry. The paper presents the principles of using neural networks and elements of artificial intelligence in the processes of production, transmission and consumption of electricity. It has been revealed that the use of artificial intelligence in the electric power industry will make it possible to minimize disruptions in power supply.
\end{abstract}

\section{Introduction}

In recent years, the Russian economy is undergoing transformations associated with the transition to innovative and digital technologies. Such a need arose because of the need to reduce production costs, save resources, improve environmental safety, reduce industrial and man-made disasters, etc. To date, all sectors of the national economy have begun to develop programs and projects related to the transition of industries to digital technologies, including the electric power complex [10;13-15].

In the modern world, one of the most important trends in the digital and information industry is the development and implementation of artificial intelligence algorithms. Today, in all spheres of human activity machine learning technologies, in-depth data analysis, as well as intelligent computer systems can be met. There are computers with speech and faces recognition, unmanned vehicles, machine neural networks in exchange trading, etc., all this is the result of the introduction and development of digitalization.

However, it is not possible to call it artificial intelligence, because only its individual elements, methods and technologies have been created. There is still no "ideal" artificial intelligence, since the main task has not been solved - creating a machine comparable to the human brain in terms of capacity, capabilities, and to a lesser extent on the architecture of processes and networks consisting of billions of neurons. An "ideal" machine has yet to be created, but it is already obvious that it will have a sufficient number of applications.

\section{Materials and methods}

The purpose of this study is to analyze and develop proposals for the introduction of artificial intelligence in the electric power industry. To achieve this goal, we have proposed the following tasks:
- analyze the existing systems of using artificial intelligence in industry;

- develop proposals for the implementation of artificial intelligence in the electric power complex of the Russian Federation.

In this study was used the methods of statistical, factor, historical, comparative, logical, economicmathematical and system analysis, the method of expert assessments, which allowed to formulate proposals for the introduction of artificial intelligence in the electricity industry.

\section{Results}

Artificial neural networks are the first step to a fundamentally new information analysis system. They are mathematical and computer models that imitate the work of biological neurons, that is, it is a system of interacting processes, built on the principle of connecting the nerve cells of the human brain (Fig. 1). It should be noted that they differ from the usual machine algorithms by the ability to learn, memorize and recreate images, identify patterns, memorize and analyze information and

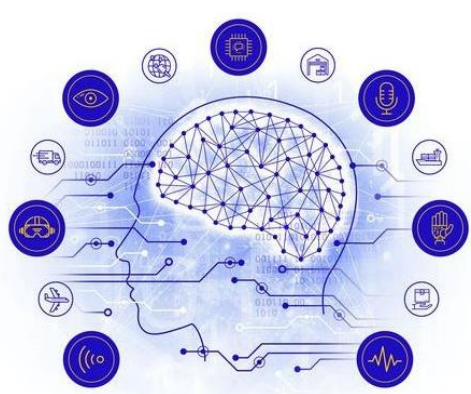

produce results.

Fig. 1. The concept of artificial intelligence

Processes of artificial neurons using nonlinear functions and activation algorithms convert incoming 
signals to outgoing ones, which then go to the next processor and continue to transform. Thus, artificial neurons form networks and layers in which connections are created, repaired, maintained and destroyed using special signals [1].

As for artificial intelligence, there is no universally accepted definition for artificial intelligence, in this regard, by artificial intelligence we mean a machine system capable of learning, using objective knowledge and experience, solving creative problems like the human brain and inventive tasks without going through options, build strategies and apply abstract concepts [2].

Digitalization and artificial intelligence penetrate into most sectors of the economy, including the electric power complex. The digitization of energy requires the development and widespread use of end-to-end technologies, including the industrial Internet, components of robotics, wireless communications, artificial intelligence, etc.

Over the next four years, it is planned to create a unified digital environment for key electric power players in Russia. Already announced a global strategy for the digitalization of the industry, which will lead to the creation of the "Internet of energy", which, in turn, will reduce the network losses by thirty percent and stimulate import substitution [3]. American experts from the company Indigo Advisory Group LLC note that the potential of artificial intelligence will be revealed in the case of creating networks of the future. It is intellectual technologies that make it possible to increase the efficiency of operations, and also to analyze unstructured data, which now make up about $80 \%$ of information in companies.

In Russia, only a few companies are engaged in such developments. These include both startups and longknown concerns [4].

The main tasks solved by artificial intelligence are presented in Figure 2.

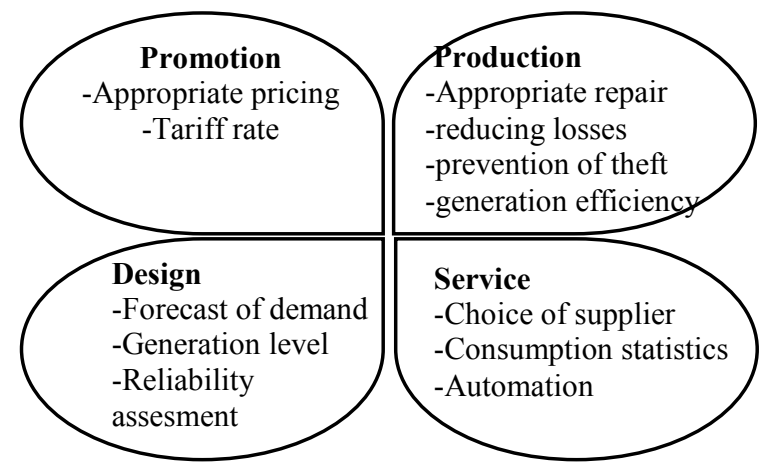

Fig. 2. Tasks of artificial intelligence in Energy industry

Consider the tasks in more detail:

1. At the design level, issues are being addressed to improve energy demand forecasting, as well as generation level, assessment of the reliability of power generating equipment, automation of relay protection systems and automation with increasing load on power plants.

2. At the production level, optimization of preventive maintenance of equipment, increase of efficiency of generation, reduction of losses and prevention of thefts of energy resources.

3. At the promotion level, optimization of price depending on the time of year and day, and the tariff dynamics is also determined and justified.

4. At the service level, questions are solved on the automatic selection of the most profitable supplier, detailed statistics on energy consumption and energy resources are provided, automated customer service is provided, and energy consumption issues are optimized taking into account customer habits and behavior [5].

Highlighting the main areas of application of artificial intelligence in the power industry, it is necessary to dwell on the following principles:

1. Forecasting. The subtasks include:

- forecasting the consumption and production of electricity;

- optimization of equipment operation during peak hours, etc.

In particular, researchers pay special attention to renewable energy and therefore clarify how solar energy and wind industry can benefit from the use of special, so-called, artificial intelligence applications. Today, artificial intelligence algorithms in forecasting issues are used in many countries of the world and, as a rule, are compared with weather conditions of a given area. For example, IBM, in conjunction with the US Department of Energy (US Department of Energy), is implementing the SunShot initiative, within which a self-learning program allows you to reliably predict the production of stations operating on non-carbon renewable resources (solar, wind and hydro). The algorithm uses a large amount of retrospective data along with information about weather monitoring in real time [2]. In addition, in the USA, Xcel is already using artificial intelligence algorithms to process weather data, which allows it to optimize the performance of wind power plants [2].

Most often in electric power industry, artificial intelligence is used to evaluate and predict the technical condition of equipment. For example, it is possible to identify "abnormal events" in production processes that are invisible to station workers. With the help of artificial intelligence, parameters that are difficult to calculate in real time are predicted: "health index" of installations, coefficient of efficiency (COP), and so on. On the basis of the obtained indicators, the power engineers receive recommendations for repairs and formed lists of defects $[4 ; 16]$.

2. Improving energy efficiency. The main task is to monitor data on actual energy consumption. The point is that there is the possibility of optimizing and reducing energy consumption through the introduction of artificial intelligence. An example is the neural network used by the British company Deep Mind Technologies Ltd, which contributed to the reduction of energy consumption (about 40\%) [2].

At General Motors, using artificial intelligence algorithms made it possible to increase the efficiency of wind turbines by $5 \%$, while maintenance costs were reduced by $20 \%$ [4]. There are examples in terms of improving energy efficiency. So, the American company Verdigris Technologies has developed software to 
optimize the energy consumption of commercial buildings, the premises of which are equipped with sensors. The use of this program to optimize the work of the kitchen of the W Hotel San Francisco for three months made it possible to identify the causes and eliminate the inefficient energy consumption of $\$ 13$ thousand per year [2].

3. Intellectualization. The main subtasks of this direction are:

- processing the results of monitoring of energy facilities and formation of conclusions;

- load management;

- effective information transfer;

- convenient access to data.

An example is also one of the UK companies National Grid UK, which uses artificial intelligence algorithms and drones to analyze and monitor the state of network objects for wear, corrosion and malfunctions. In the future, this artificial intelligence will allow to assess the overall condition of the asset, the need for its modernization or replacement $[2 ; 6]$.

PowerScout has received two grants from the US Department of Energy for the development of smart home network and consumer cost reduction programs, taking into account the integration of renewable sources. Programs also use artificial intelligence algorithms.

An interesting application of artificial intelligence methods was reported by the German company Schleswig-Holstein Netz AG, which operates electrical networks in the federal state of Schleswig-Holstein. Here, the self-learning network is used to determine the locations of the alleged damage. As initial data, this network uses information on perfomance of components of electrical networks and the repairs carried out, as well as information on loads and weather conditions [1].

The American company Air Fusion, which uses unmanned aerial vehicles to study the state of highvoltage power lines and wind turbines, uses software with artificial intelligence algorithms to process monitoring results. The neural network helps to solve the pattern recognition problem, for which thousands of images of damaged wind turbines are loaded into the program during the training process [7].

Startup Upside Energy provides a service that distributes energy in the power grid using machine learning algorithms and artificial intelligence. Under the control of artificial intelligence, power stations, energy storages, and solar batteries are already working. That is why, experts believe that artificial intelligence will soon become an integral part of energy. Upside Energy creates a virtual energy storage. It reduces the load on the power plant. If somewhere there is not enough energy, then under the usual scenario, power plants are forced to increase speed by burning additional fuel. Upside Energy uses predictive algorithms and knows in advance where and at what point the network will overload. With such information, the system automatically redirects the power of neighboring stations and small energy sources to compensate for voltage surges. As a result, the surplus is consumed efficiently, and additional fuel is not needed to generate additional capacity.
The service coordinates the work of batteries and generators at 40 sites. Meanwhile, computing power allows you to support thousands of objects, including electric vehicles, solar panels and uninterruptible power supplies. Upside Energy has signed an agreement with the UK's national energy network to provide precise frequency control services. This means that in case of system overload, the company takes on the job of reducing the load.

A similar program is implemented in the Netherlands. Eneco sells Tesla PowerWall batteries at half price. In exchange for such a discount, the buyer must connect to the "virtual power plant". This means that $30 \%$ of its batteries will be reserved for the needs of a quarter, district, or city. In the event of a system overload, the program will direct these powers to eliminate the situation that has arisen, and the battery owner receives money for the generated electricity [8].

In the power industry, any processes take place consistently and require immediate decision-making, in case of violation of the algorithm for performing the assigned tasks. This is especially true for nuclear energy, which is one of the high-tech industries where Russia retains its leading position. If we consider the introduction of artificial intelligence in this industry, then it will help solve a number of problems (Table 1).

Table 1. The main results of the use of artificial intelligence in atomic energy.

\begin{tabular}{|c|c|c|}
\hline № & Task & Result \\
\hline 1 & Reactor safety & $\begin{array}{c}\text { Identification the location of } \\
\text { defects }\end{array}$ \\
\hline 2 & $\begin{array}{c}\text { Nuclear power plant } \\
\text { status check }\end{array}$ & $\begin{array}{c}\text { Quick data flow analysis, } \\
\text { comparison with reference and } \\
\text { then problem detection }\end{array}$ \\
\hline 3 & $\begin{array}{c}\text { Catastrophic risk } \\
\text { management }\end{array}$ & $\begin{array}{c}\text { Preventing emergency } \\
\text { situations, reducing danger }\end{array}$ \\
\hline 4 & $\begin{array}{c}\text { Creating digital } \\
\text { models of nuclear } \\
\text { power plants }\end{array}$ & $\begin{array}{c}\text { Ensuring the safety of nuclear } \\
\text { power plants, the collection of } \\
\text { all technical, technological and } \\
\text { operational information }\end{array}$ \\
\hline 5 & $\begin{array}{c}\text { Artificial Intelligence } \\
\text { and Automated } \\
\text { Process Control } \\
\text { System (APCS) }\end{array}$ & $\begin{array}{c}\text { Appropriate resource allocation, } \\
\text { increasing production efficiency }\end{array}$ \\
\hline 6 & $\begin{array}{c}\text { Optimization of } \\
\text { design processes }\end{array}$ & $\begin{array}{c}\text { Reduced development cycle, } \\
\text { cost reduction. Solving complex } \\
\text { problems }\end{array}$ \\
\hline 7 & Advancement of \\
science & $\begin{array}{c}\text { Fast processing of data from } \\
\text { scientific experiments and their } \\
\text { further application }\end{array}$ \\
\hline 8 & Technological \\
process & $\begin{array}{c}\text { Accelerate the pace of } \\
\text { innovation and productivity } \\
\text { growth. Formation of new } \\
\text { industries and the dynamic } \\
\text { development of existing ones }\end{array}$ \\
\hline 9 & Cybersecurity & $\begin{array}{c}\text { Finding vulnerabilities, writing } \\
\text { codes and machine algorithms }\end{array}$ \\
\hline
\end{tabular}

Let us consider in more detail the main results of the application of artificial intelligence in atomic energy.

1. Reactor safety. Neural networks, analyzing video images from special cameras, which will allow to determine the location of cracks and defects in reactors. 
2. Nuclear power plant status check. Inspection and control of all components of reactors, units, assemblies and premises of nuclear power plants require enormous resources. Artificial intelligence is able to more quickly analyze the flow of data coming from sensors, surveillance and control systems, compare them with the reference data of the information base, and then using the data fusion algorithms to ascertain the presence or absence of a problem. Using such systems, it is also possible to analyze the environmental situation in the area of a nuclear power plant, to monitor pollution and emissions.

3. Catastrophic risk management. These include risk management of uncontrolled reactions and attacks on nuclear power plants. This is necessary in order to prevent the occurrence of these situations, as well as to reduce the level of their danger.

4. Creating digital models of nuclear power plants. Any station throughout their life cycle must be periodically modified, subjected to replacement and modernization of components and assemblies. Creating digital models of nuclear power plants with elements of artificial intelligence will allow you to accumulate information about all technical, technological and operational processes and monitor them in real time, ensuring the safety of nuclear power plants.

5. Artificial intelligence and automated process control system (APCS) at the nuclear industry enterprises. Control systems based on algorithms of artificial intelligence will be more efficient than conventional systems of automated process control systems. And work in conjunction will provide automation of the main operations in production, will increase its efficiency due to the optimal distribution of material, energy and information resources of the enterprise.

6. Optimization of design processes. Artificial intelligence can shorten the design cycle of new types of products and reduce the overall cost of research and development, as neural network technologies will help developers to solve complex engineering and scientific problems.

7. Advancement of science. The base of scientific knowledge is limitless. It is required not only its systematization and analysis, but also active use in research, in setting tasks for new experiments and identifying patterns in existing processes. This will save a significant amount of man-hours, as well as conduct a qualitative analysis and modeling of production and technological processes. Artificial intelligence will be useful when conducting any additional fundamental research in the field of the thermodynamics of nuclear fuel and hydrogen plasma, neutron physics and magnetic hydrodynamics. Artificial intelligence will be useful for the functioning of data processing complexes of scientific experiments. At the same time, it should be noted that neural networks will have access to any kind of information: scientific, political, military, which will help to combine knowledge and help in the development of nuclear physics, quantum chemistry, and so on.

8. Technological process. Artificial intelligence can be a technology that transforms the entire economy, because it has the potential to accelerate the pace of innovation and productivity growth. This could lead to a new industrial revolution. In this case, the automation of labor will reach a level at which the relationship between labor and capital will change. Obviously, digital technologies have a huge competitive advantage. A country actively using algorithms of artificial intelligence will be able to form new sectors of the economy and achieve a strategic advantage in already existing areas.

9. Cybersecurity. Artificial intelligence has exceptional capabilities in cyberspace. $\mathrm{He}$ is able to quickly find vulnerabilities, write codes and machine algorithms. It is believed that in the near future cyber attacks will become more complex and very dangerous; this will create serious problems for man-controlled defenses [2].

\section{Discussion}

The Russian Federation is one of the few countries that have been developing artificial intelligence technologies as well as neural networks for several decades [2]. In 2017 , by order of Rosstandart, a technical committee on standardization "Cyber-physical systems" was organized (Fig. 3). The task of this committee is to work together with scientists and the business community to develop regulatory documents in selected areas of technology. We are talking about terminology, data exchange formats, software interfaces, test methods, etc. The committee should also participate in the creation of international standards in order to protect the interests of Russian technology companies in the global market.

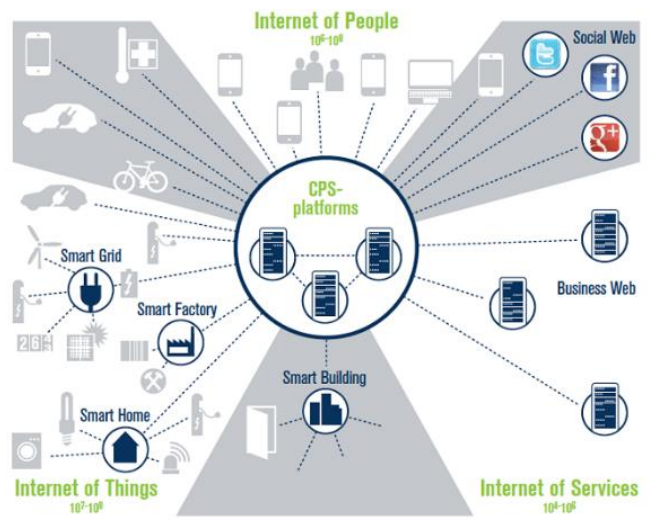

Fig. 3. Cyber-physical systems

Standardization of artificial intelligence technologies will affect almost all areas of activity. In the field of public security, it is worth to mention the recognition of images and speech, the forecast of human behavior. In medicine, this will affect remote medical consultations, the determination of susceptibility to diseases, their early diagnosis, decision support systems for doctors. Intellectual systems also will not bypass such industries as agriculture, transport and logistics, as well as "smart homes".

In the field of "smart energy" artificial intelligence is necessary for the development of new technologies in the industry. This will improve the quality of service and 
monitoring of electrical networks and, consequently, optimize the costs of their operation. The introduction of algorithms will also remove the regulatory barriers to developing new products and expanding the scope of services provided.

Standardization is one of the necessary conditions for the "digital transformation" of markets. This is due to the fact that it allows you to unify technical requirements and is able to ensure the joint operation of systems from different manufacturers. In particular, standards are necessary for the compatibility of various user devices.

In the Russian Federation, the development of the neural network is the responsibility of the STI Competence Center, which plans to develop technologies to combat blackouts in electrical power systems. They will constantly replenish the database with relevant information from the territory of its work, as well as form recommendations on how to optimize repairs. The neural network will allow the power system to adjust itself automatically to ever-changing power consumption modes and recover by using predictive models, which should minimize human participation in management to a minimum [9].

Russian companies specializing in the application of artificial intelligence algorithms in the industry, launch their projects in Russian energy holdings. One of such projects is Digital Energy. It is about building a unified platform on which they will use artificial intelligence technologies. This project is aimed at solving industry problems of the electric power industry.

The Clover Group startup also works in the energy segment. The company is engaged in predictive analytics for industrial equipment: from auxiliary elements to turbine units. Such developments make it possible to determine which equipment should be subject to repair in order not to impair its performance. It is noted that the introduction of algorithms of artificial intelligence in the energy sector will provide a huge economic effect on enterprises.

In 2017, together with the St. Petersburg Polytechnic University, Siemens Concern opened a laboratory called Industrial Systems of Artificial Intelligence. This laboratory allows you to develop embedded systems of artificial intelligence, server equipment, as well as data storage systems and supercomputers, which are designed to solve problems in the field of machine learning. The laboratory plans to monitor and diagnose industrial systems and devices. The results of development will be required in high-tech industries, including in the power industry for the production of electricity [11].

\section{Conclusions}

Thus, artificial intelligence technologies in Russia have prospects for development. Of course, significant targeted funding is needed to achieve meaningful results. The interaction of scientific institutes and universities with businesses, where artificial intelligence technologies are also developing, is very important. The attention of the authorities and the society, their understanding of the importance of the tasks facing the country are needed.

With regard to the power industry, the integration of artificial intelligence in the industry will help optimize and improve efficiency in all aspects of the production, transmission and consumption of energy. It should be noted that the development of the electric power industry is a step towards the development of other industries. That is why the transition to the digital industry is impossible without the digitalization and intellectualization of the power industry.

\section{References}

1. A. Mogilenko, Application of artificial intelligence algorithms in the global energy industry. Energy and Industry of Russia, 2018, no 7, p. 23.

2. A. Losev, Artificial Intelligence in Nuclear Power. Atomic Expert, 2018, no 3-4, pp. 35-43.

3. How does the domestic business connect to digitalization projects in the power industry, 24 RosInfo, URL: http://24ri.ru/down/open/kak-otechestvennyjbiznes-podkljuchaetsja-k-proektam-cifrovizacii-venergetike.html.

4. How artificial intelligence is used in the Russian energy industry, 24 RosInfo, URL: http://24ri.ru/down/open/kak-iskusstvennyj-intellektprimenjajut-v-rossijskoj-energetike.html.

5. Artificial Intelligence, TAdviser, URL: http://www.tadviser.ru/index.php/\%D0\%9F\%D1\%80\% D0\%BE\%D0\%B4\%D1\%83\%D0\%BA\%D1\%82:\%D0\% 98 D1\% 81\% D0\% BA\% D1\% 83\% D1\% 81\% D1\% $81 \%$ D1\% 82\% D0\% B2\% D0\% B5\% D0\% BD\% D0\% BD\% D1\% 8B\% D0\% B9 \% D0\% B8\% D0\% BD\% D1\% 82\% D0\% B5\% D0\% BB\% D0\% BB\% D0\% B5\% $\begin{array}{lllllllll}\mathrm{D} 0 \% & \mathrm{BA} \% & \mathrm{D} 1 \% & 82 & \text { (\% } & \mathrm{D} 0 \% & 98 \% & \mathrm{D} 0 \% & 98,\end{array}$ _Artificial_intelligence,,$\overline{\mathrm{A}} \mathrm{I})$.

6. A. Vaughan. AI and drones turn an eye towards the UK's energy infrastructure. The Guardian, December, 2018, pp. 48-52.

7. Artificial intelligence in electrical networks, ESS, URL: https://electricalnet.ru/blog/iskusstvennyiintellekt-v-elektricheskih-setyah-innovatsii-v-energetike.

8. Artificial Intelligence Efficiently Distribute Energy in Electricity Networks, Eenergy.media, URL: https://eenergy.media/2017/02/05/ii-effektivnoraspredelit-energiyu-v-elektrosetyah.

9. S. Ivanov Artificial Intelligence will be able to deal with blackouts in power grids. Hi-Tech, 2019, no 1, pp. 28-31.

10. V. Pulyaeva et al 2019 IOP Conf. Ser.: Mater. Sci. Eng. 537042033

11. How artificial intelligence is used in the Russian energy industry, Innoprom, URL: https://www.innoprom.com/media/letters/kakiskusstvennyy-intellekt-primenyayut-v-rossiyskoyenergetike. 
12. D. Morkovkin et al 2019 IOP Conf. Ser.: Mater. Sci. Eng. 537042064.

13. A. Gibadullin, V. Pulyaeva, Y. Yerygin, The Need for a Digital Substation during the Digitalization of Energy. International Youth Scientific and Technical Conference Relay Protection and Automation, RPA, 2018, no 8537223.

14. E. Kamchatova, A. Vasilieva, N. Lyasnikov, M. Dudin, N. Vysotskaya, Eneggy saving management in urban economy and industry. International Journal of Civil Engineering and Technology, 2018, vol. 9, no 6, pp. 1423-1429.

15. V. Linnik, Yu. Linnik, Priority directions of innovative development in oil and gas complexat the Siberian Federal District. Upravlenie, 2019, vol. 7, no 1, pp. 40-49. DOI: 10.26425/2309-3633-2019-1-40-49.

16. A. Gibadullin et al 2019 IOP Conf. Ser.: Mater. Sci. Eng. 537042031. 